\title{
The founding principles of Sport for Development programmes in Zimbabwe and challenges impeding effective programme implementation.
}

\author{
Edmore Nhamo ${ }^{1}$, Simbarashe Magonde ${ }^{2}$ \\ ${ }^{1,2}$ Department of Health Sciences, Faculty of Science and Technology, Zimbabwe Open University, Zimbabwe.
}

\begin{abstract}
This article reviews, discusses and analyses the founding principles that have motivated and inspired the formation of two major Sport for Development (SFD) initiatives with specific reference to circumstances in a developing country like Zimbabwe. The paper proceeds by analysing the numerous challenges which Zimbabwe has faced in her quest to implement Sport for Development initiatives with specific reference to the two major SFD initiatives i.e the Community Sport Development project (CSDP) and the Youth Education through Sport (YES) programme. The paper also projects forward by reviewing solutions for effective implementation of these Sport for Development programmes in Zimbabwe in order to enhance the achievement of the intended development goals.
\end{abstract}

Keywords: Sport for Development, founding principles, challenges, YES, CSDP.

\section{Introduction}

This paper reviews the founding principles ie the legal, statutory, policy and partnership agreement initiatives that have influenced the development of two major Sport for Development (SFD) programmes in Zimbabwe. The two major SFD programmes of particular concern to this study are the Youth Education through Sport (YES) and the Community Sport Development project (CSDP). The article begins by giving a brief overview of the SFD concept, proceeds to give a brief background of the two major SFD programmes in Zimbabwe and then attempts to give a complete picture upon which these Sport for Developmet initiatives are premised. In addition the article focuses on some of the challenges associated with implementing SFD programmes in Zimbabwe especially the CSDP and proposes possible solutions to alleviate these challenges. This review is important because it attempts to enhance our understanding of the principles which influenced the conception of SFD programmes. It is the Authors hope that this understanding will assist Zimbabwean stakeholders and other interested parties to appreciate the origins of the objectives which these SFD programmes seek to address. Understanding the challenges faced in the implementation of SFD programmes on the other hand will also help in identifying possible solutions in order to enhance the achievement of the envisaged national development goals and objectives.

\section{The Concept Of Sport for Development}

Sport and physical activity are rapidly gaining recognition as simple, low-cost and effective means of achieving development goals ${ }^{[1]}$. Over the past decade $\mathrm{UN}$ agencies, international sport federations, international and national non-governmental organisations and national governments have been trying to utilize sport as a tool for development and peace ${ }^{[1]}$. It is apparent from the literature reviewed that understanding the concept of sport for development (SFD) requires a good understanding of two basic underlying concepts i.e. "Development" and "Sport" and how effective the combination and interplay of the two can be as a tool to enhance human and social development ${ }^{[2]}$. The Commonwealth Games Association of Canada (CGAC) ${ }^{[2]}$ describes development as a concept which is concerned with building a better world. In this context building a better world refer to providing people with opportunities to lead long and healthy lives and enhancing access to resources necessary for a decent standard of living ${ }^{[2]}$. On the other hand The Commonwealth Games Association of Canada ${ }^{[2]}$ defines sport as encompassing all types of physical activities and all levels of participation. It can be deduced from these two definitions that Sport for Development (SFD) is an attempt to use physical activities to build a better life for people. In the realm of SFD, sport is regarded as an integral component of social, economic and human development and a necessary underpinning to health and well being [2]. When integrated into the broader framework of development goals, priorities, programs and activities sport can address basic needs and advance sustainable human and social development ${ }^{[2]}$.

However as reported by Hancork, Lyras and $\mathrm{Ha}^{[3]}$, it is important to recognize that from a social and cultural perspective sport can be understood to have dualistic qualities. On one (negative) hand sport is known to possess the potential to divide people and nations by promoting such ills as corruption, discrimination, drug abuse, nationalism, racism and violence ${ }^{[4,5,6,7]}$. On the other (positive) hand sport is strongly believed to serve 
as a vehicle for advancing positive social change ${ }^{[5,7,8,9,10]}$ through the promotion of values such as democracy, justice and human rights ${ }^{[11,12]}$. Many authorities believe sport has the potential to resolve social problems including deficiencies in education, the spread of diseases, poverty, inter-ethnic conflict, and gender imbalances $[5,6,10,12,13]$. In the Sport for Development field proponents, policy makers and practitioners have continued to emphasise and advocate the positive development benefits that can be accrued through participation in sport ${ }^{[14}$, $15,16,17]$ and this has resulted in the SFD concept gaining international recognition.

\section{A Brief Background Of Major Sport for Development Programmes In Zimbabwe.}

There are two major SFD programmes in Zimbabwe namely, the Community Sport Development project (CSDP) and the Youth Education throught Sport programme (YES). It is apparent that even though the two programmes are distinct they are closely interelated since the YES was the basis of the CSDP and both share common basic characterristics.

\subsection{Youth Education through Sport Programme}

The Youth Education through Sport (YES) programme was initiated by the Sports and Recreation Commission in 1999. The Sport and Recreation Commission (SRC) is the supreme sporting body in Zimbabwe tasked with the responsibility of controlling, regulating, assisting, promoting, coordinating and generally overseeing the promotion and development of sport and recreation in the country ${ }^{\left[{ }^{[3]}\right.}$. The Sports and Recreation Commission also ensures the proper administration of organizations undertaking the promotion of sport and recreation and promotes the highest standards of sportsmanship and governance ${ }^{[3]}$. The purpose of the YES programme is to impart life skills to the youthful athletes using sport as a platform ${ }^{[3] .}$ The Youth Education through Sport programme is made up of three components which are Sport, Peer Education and Community projects ${ }^{[3]}$. In the YES programme youth teams compete in all three components. The three components are given equal weighting in the competitions and hence command equal points for purposes of judging the winning teams. ${ }^{[3]}$ The programme is implemented in all ten provinces of the country. Teams start competing at ward level through to district, provincial then regional levels and the competitions culminates in a national "YES" festival ${ }^{[3]}$. In the recent past the YES programme has been used extensively to address key developmental issues such as HIV/AIDS. For many years the YES festivals were re-christened Kicking AIDS out Festivals because of the emphasis the programme placed in dealing with HIV and AIDS issues.

In implementing the YES programme the Sports and Recreation Commission enlisted the services of relevant technical and funding partners who include the Norwegian Olympic and Paralympic Committee and Confederation of Sport (NIF), UNICEF Zimbabwe, Zimbabwe National AIDS Council, Zimbabwe National Family Planning Council, Child Line Zimbabwe, Forestry Commission and Plan Zimbabwe ${ }^{[3]}$. Also in order to ensure that there is depth in the running of the programme a national committee comprising of selected volunteers was put in place to ensure the smooth implementation of the programme ${ }^{[3]}$. Each province also has a committee of selected volunteers who are responsible for administering the programme. The YES programme is the predecessor of the Community Sport Development programme and the two programmes share a common base of funding partners.

\subsection{Community Sport Development Programme}

The Community Sport Development Programme (CSDP) is a grassroots "Sport for all" programme with an expanded development of the Youth Education through Sport (YES) component ${ }^{[3]}$. The CSDP is a strategy that was crafted by the SRC to ensure that sport is taken to the communities throughout Zimbabwe and was launched in $2009{ }^{[3]}$. The programme which is currently implemented in 20 prioritized districts is being funded by UNICEF Zimbabwe and the Norwegian Olympic and Paralympic Committee. The CSDP is being implemented in the 20 districts through community structures such as District Sport Development Committees (DSDCs). The DSDCs are committees made up of volunteers and strategic individuals such as District Administrators (DAs) and District Education Officers (DEOs). The DAs assume the role of Patrons for these Committees while the DEOs assume a supervisory role over the operations of the DSDCs. ${ }^{[3]}$. As SRC ${ }^{[19} \mathrm{p}^{1]}$ posits, "The CSDP is an empirical model ideal for sport and social development that has worked well in other countries around the world. Through comprehensive research, the model has been adapted to suit the setting of rural and high density communities of Zimbabwe".

The Community Sport Development Project (CSDP) is therefore a community development initiative which focuses on the formation of model communiy sports clubs ${ }^{[19]}$. A community sports club is defined as a multi-disciplinary club offering a number of sport disciplines and other services to its members ${ }^{[19]}$. It is driven by local people inorder to achieve their objectives of physical activity, sport and community development ${ }^{[20]}$. The community sport club model is implemented in all communities at specific designated centres such as urban and rural service/business centres ${ }^{[19]}$. The CSDP was piloted using four prioritised disciplines, namely football, netball, athletics and volleyball ${ }^{[20]}$. The overall goal of the CSDP is to develop and implement an 
intergrated community sport delivery system that includes opportunities for life skills development for youths in Zimbabwe ${ }^{[20]}$. The specific objectives of the CSDP were stated as, "to enhance the existing legal framework of governance systems to guide the implementation and coordination of the CSDP in Zimbabwe; to develop new and reiforce existing community sports structures and intergrate them into the national sport system; to activate community sport and recreation programmes for youths that enhance life skills training" ${ }^{[3]}$. The YES and the CSDP are both national strategies that have been used by the Sports and Recreation Commission of Zimbabwe to promote mass participation in sport and community development.

\section{Key Founding Principles And Policies}

It is apparent according to SRC ${ }^{\left[20 \mathrm{pl}^{1}\right]}$ that the conception of both the YES and the CSDP in Zimbabwe, "can be traced back to a very strong bond emanating from a common need by a number of legal, statutory, policy and agreement initiatives to see sport providing an effective forum for promoting health, education, inclusion, peace and community development."

It is the purpose of this article to review and enhance our understanding of the national principles and policies that directly influenced the development of SFD initiatives in Zimbabwe with specific reference to the YES and the CSDP programmes. The key founding principles which were identified include the following:

\subsection{The Physical Education, Sport and Recreation Policy}

The then Ministry of Education, Art, Sport and Culture in Zimbabwe produced several policy guidelines on Physical Education (PE) and Sport. These polices include the National Sport and Recreation Policy of 1996 as reviewed in $2006^{[20]}$, The policy was supported by the Ministry of Education, Sports, Arts and Culture Circular number 2 of $1994^{[22]}$ and Circular number 5 of $2005^{[23]}$. The content of the policy and the emphasis of the subsequent circulars sought to promote "Sport for all" (mass participation) in the country. As SRC ${ }^{[19]}$ explains the intention of the sports policy is to provide sport and recreation to all people in the country irrespective of their ability, gender, age, race, geographical location or socio-economic status. This policy fosters the promotion of sport and recreation in the country including taking sport to people in all parts of the country, thus creating opportunities for sport and recreation for all and providing an enabling environment for the fulfillment of the Millennium Development Goals (MDGs). The Physical Education and Sport policy ${ }^{[21]}$ and circular number 2 of $1994^{[22]}$ therefore appear to have formed a strong foundation in the formation of the YES and CSDP in Zimbabwe as their content are inherent in the objectives of the two SFD programmes.

\subsection{The Sport and Recreation Commission Act}

The development of the YES and the CSDP also appears to have been influenced by the Sports and Recreation Act 25.15 of 1991, revised $1996^{[24]}$. This is the Act of parliament which gives the Sports and Recreation Commission the mandate to coordinate, control, promote, develop and generally oversee sport and recreation in Zimbabwe. In discharging these responsibilities, the SRC is guided by other national policies, specifically those to do with the youth, gender, HIV and AIDS, people with disabilities and the eradication of social scourges ${ }^{[18]}$. This appears to be the reason why the SRC took a leading role in the conceptualization and implementation of the YES and the CSDP programmes.

\subsection{National Policies on Youth, Gender, People with Disabilities and HIV/AID}

As explained earlier on the CSDP is a grassroots "Sport for all" programme with an expanded development of the Youth Education through Sport (YES) component. The YES component of the CSDP found its basis on the integration of relevant national policies on youth, gender, people with disabilities ${ }^{[25]}$ and HIV and AIDS ${ }^{[26]}$. The logic behind the YES programme is premised on the pulling power of sport, where sport brings the youth, the girl child, women and people with disabilities together thereby creating a fertile ground for positive life skills development.

\subsection{The Millenium Development Goal}

According to Ogi ${ }^{27]}$, in the year 2000, at the Millenium Summit in New York, the leadership of 189 countries of the world agreed to implement the Millenium Development Goals (MDGs) by 2015. Emanating from this summit are eight MDGs.

In October 2003, the Secretary General of the United Nations (UN), Kofi Annan published a report entitled "Sport for Development and Peace: Towards achieving the Millenium Development Goals" the report concluded that sport at all levels, from play and physical activity to elite and competitive is a powerful and cost effective way to advance the MDGs ${ }^{27]}$. This report is important because it represented an important link betweeen the world of sport and the Millenium Development Goals. According to Ogi ${ }^{[27 p}{ }^{6]}$ a gathering of heads of states also attended a world summit at the United Nations (UN) headquarters in September 2005 and further reinforced the role of sport in development stating, "We underline that sports can foster peace and 
development and contribute to an atmosphere of tolerence and understanding..." In 2004 the Zimbabwean Government adopted the MDGs and launched its local chapter of the implementation of the MDGs in apparent recognition of the above mentioned developments ${ }^{[19]}$. According to SRC ${ }^{[19]}$, the use of sport in Zimbabwe was thus recognised as part of the multisectoral strategy to achieve the implementation of the MDGs by 2015. The conceptualisation of the YES and the CSDP was therefore a deliberate strategy by SRC to contribute towards the achievement of the MDGs through the use of sport.

\subsection{The Tripartite Cooperation Agreement}

The founding principles described above were used as justification by the SRC in a partneship meeting they held with UNICEF Norway and the Nowergian Olympic and Paralympic Committee and Confederation of Sport (NIF). The partnership meeting resulted in the Tripartite Cooperation Agreement (TCA) of 3 December $20077^{[28]}$ which concequently gave birth to the CSDP in 2008. The partneship's main goal was stated as "to implement the CSDP" ${ }^{18]}$. The TCA stipulated that in the implementation of the CSDP each patrner had a different but specific role to play. As SRC ${ }^{[19]}$ explains, the role of the Sports and Recreation Commission in the CSDP was to take care of the technical issues to do with implementation while the other partners provided advise and financial support. According to James ${ }^{[29]}$, the SRC thus managed to solicit financial support from UNICEF Norway and NIF amounting to two million United States dollars (US\$2 million) which was in the form of vehicles, office equipment, stater kits and cash resources.

James ${ }^{[29]}$ states that the CSDP itself was also justified on the basis of an assessment of the Youth Education Through Sport (YES) programme in 2007 which revealed that although sport was being accessed by the youth, there were no proper structures in the communities within which people could be properly organised. The assessment of the YES programme led to a baseline survey which was designed to establish the extend to which the communities were organised in sport. As James ${ }^{[29]}$ further explains, the survey noted that there was need to organise communities into multi-discipline sports community clubs. Findings from the YES assessment and the baseline survey were used by SRC together with the founding principles described above to convince and pacify the sceptical partners on the need for the CSDP. The multi-sports community club structure thus became the basis of the CSDP dully supported by elements of the YES programme.

\section{Challenges Of Implementing Sport For Development Progrmmes In Zimbabwe}

In spite of the popularity of SFD programmes in many countries,there are many challenges which characterise attempts by nations to intergrate SFD initiatives into their national development strategies and many countries are struggling to meet the specified targets ${ }^{[27]}$. The CSDP and the YES are no exception to these challenges. The CSDP seems to have had its fair share of implementation ploblems and challenges. It was observed that from inception the CSDP was beset with implementation problems which resulted in a number of false starts and a one and half year late roll out. Some of the problems which delayed the initial roll out of the CSDP included SRC compliance and risk issues, the perfection of procedures for the release of resources by UNICEF, the cholera outbreak in Zimbabwe in 2008 and the hyper inflationary economic environment obtaining in the country at that time which was very unfavorable.

A Mid Term Assessment Survey which was conducted by SRC in 2010 to establish whether the CSDP is meeting its objectives among them being the establishment of Community Sport Clubs and the promotion of life supporting social activities for people in their respective communities identified the following implementation challenges:

The study identified that the envisaged scope of implementation for the CSDP was over-ambitious and unmanageable. The SRC, UNICEF and NIF as parties to the TCA and the operatives implementing the project agreed to this finding ${ }^{[20]}$.

The study also discovered that funding and material support for the CSDP had not been released timely causing separate units of the programme to be held simultaneously instead of being held sequentially to allow dissipation from one level to the other. Such programme pile up divided the attention of the SRC operatives and the people they serve resulting in programme implementation becoming haphazard and disorderly. Only one half of the envisaged programme deliverables had been attained by the time of the survey, which means the programme was running seriously behind schedule ${ }^{[20]}$.

It was also observed that the YES programme had also suffered similar funding challenges as those mentioned above. Very little or no funding has been made available for most of the YES lead up activities with SRC mostly funding the National Festivals. The communities tasked with running these activities were finding it difficult to source the necessary funding in an economy characterized by severe liquidity challenges and low capacity utilization by most corporate enterprises.

Findings also revealed that capacity building for club stakeholders was lagging behind. Only twenty percent (induction and tutor training) had been delivered leaving eighty percent (training in coaching, umpiring, administration and project management) yet to be done ${ }^{[20]}$. 
The implementers of the programme were not living up to their promises which they made to the clubs regarding material (viz: starter kits, tool kits and visits) and moral support. Most CSDP and YES clubs struggled and continue to struggle to acquire basic equipment such as balls ${ }^{[20]}$.

Club executives, Ward Sport Volunteer Facilitators, Athletes, and Peer Leaders who are the key operatives in the CSDP had difficulties in meeting the costs of communication, travel and subsistence when they are on CSDP business ${ }^{[20]}$. Some of the prioritized districts were found to be so distant and so vast as to require extra vehicles, fuel, tools and travel and subsistence for SRC operatives who provide leadership to the YES and CSDP. These important requirements were found to be severely and grossly inadequate ${ }^{[20]}$.

The study revealed that CSDP business was so overwhelming that it called for additional human resources at Provincial, District and Ward level to service the programme (e.g. The project had many local partners who needed to be handled in a manner that would benefit the community clubs) ${ }^{[20]}$.

Last but not least the study revealed that the achievement of the SFD objectives were also being hindered by the fact that most clubs concentrated on playing sport whilst neglecting the other key components of the project i.e. peer education and community projects thereby compromising the achievement of the envisaged objectives ${ }^{[20]}$.

\section{Recommendations}

On the basis of the above challenges the study ${ }^{[20]}$ made the following recommendations:

Clubs need to be assisted with basics such as seed equipment; tool kits, promotional material and crucial training in the shortest possible time in order to sustain activities.

To sustain the envisaged scope of implementation for the CSDP, there was need to deliver financial, material and human resources proportional to the scope of the project. The other option was to reduce the scale and maintain a given number of clubs to a point of self sustenance, wean them off and use them as models for those coming on board next. Also, advocacy activities were needed so that club members (especially those just recruited) are convinced that the programme is community owned.

Adequate and timely release of resources needed to be seriously considered. Information about funding and resource allocation also needed to be disseminated to all provinces in advance to allow careful planning. Training of club executives and other club stakeholders should be prioritized so that they acquire skills necessary for effective club management.

It was also recommended that the SRC should live up to its promises so that stakeholders don't lose heart and don't feel neglected.

SRC should consider introducing an incentive scheme for volunteers in order to ensure their retention. These incentives could include meaningful subsistence allowances when volunteers are on CSDP business and provision of motorcycles or bicycles for travelling to the prioritized Districts and Wards.

\section{Conclusion}

It can be concluded from the above review that the major sport for evelopment programmes in Zimbabwe can be traced back to a number of legal, statutory, policy and partnership agreement initiatives. These founding principles were developed primarily to ensure that sport provides an effective platform for promoting health, education, inclusion, and peace and community development. The critical founding principles that have driven and shaped the concept of SFD in Zimbabwe include the Physical Education Sport and Recreation Policy, The Sport and Recreation Commission Act 25.15 of 1991, Revised 1996, National Policies on Youth, Gender and People with Disabilities and HIV and AIDS, the Millenium Development Goals and the Tripartite Cooperation Agreement of the $3^{\text {rd }}$ of December 2007 among others. It can also be concluded from the above review that Zimbabwe faces numerous challenges in the process of intergrating Sport for Development initiatives into its national development strategies. Since some of these challenges tend to be perculiar to Zimbabwe it is a strategic challenge for Zimbabwe to continue conducting research on these challenges and also embrace the recommendations suggested in this paper in an attempt to address them.

\section{References}

[1]. Donnelly, P., Darnell, S.; Wells, S., and Coakley, J. The use of Sport to foster Child and Youth Development and Education, Literature Reviews on Sport for Development and Peace International Working Group (SDPIWG), University of Toronto, Faculty of physical Education and Health. [online] [retrieved February 26, 2011] from http://www. Literature reviews.SDP, 2007.

[2]. Commonwealth games Association of Canada: Canadian Sport leadership Corps Pilot Evaluation Project, A proposal submitted to social Development Fund of the Canadian Development Agency (CIDA) in partnership with Athletes CAN Canadian Association for health, Physical Education, Recreation and Dance (CAHPERD) Sport Canada (Department of Canadian heritage), 2007

[3]. Hancock M, Lyras A,Ha J.P . Sport for Development programmed for Girls and women: a global assessment, Journal of sport for |Development 2013 1 (1): 15-24

[4]. Chalip L. Towards social leverage of sport events. Journal of Sport and Tourism. 2006; 11(2):109-27.

[5]. Lyras A. Characteristics and Psycho-Social Impacts of an Inter-Ethnic Educational Sport Initiative on Greek and Turkish Cypriot Youth. Storrs: University of Connecticut; 2007. 
[6]. United Nations GA. Sport for peace and development: Towards achieving the Millennium Development Goals. New York: United Nations, 2003.

[7]. Lyras A. Olympism in practice: Psycho-social impacts of an educational sport initiative on Greek and Turkish Cypriot youth. The International Council for Health, Physical Education, Recreation, Sport and Dance Journal of Research, 2012; 7:46-54.

[8]. Davis-Delano L. R, Crosset T. Using social movement theory to study outcomes in sport-related social movements. International Review for the Sociology of Sport.2008; 43(2):115-34.

[9]. Jarvie G. Sport, social change, and the public intellectual. International Review for the Sociology of Sport. 2007; 42(4):411-24.

[10]. Lyras A. Sport for peace and development theory: European Association of Sport Management; Amsterdam. Netherlands, 2009.

[11]. Harvey J, Rail, G., \& Thibault, L. Globalization and sport: Sketching a theoretical model for empirical analyses. Journal of Sport \& Social Issues. 1996; 20(3):258-77.

[12]. Harvey J, Horne, J., \& Safai, P. Alterglobalization, global social movements, and the possibility of political transformation through sport. Sociology of Sport Journal. 2009; 26:383-403.

[13]. Lyras A, Welty Peachy J. Integrating sport-for development theory and praxis. Sport Management Review. 2011; 14(4):311-26.

[14]. Brady M. Laying the foundation for girls' healthy futures: Can sports play a role? Studies in Family Planning.1998; 29(1):79-82.

[15]. United Nations GA. /5: Sport as a means to promote education, health, development, and peace. New York: 2003.

[16]. Allender S, Cowburn G, Foster C. Understanding participation in sport and physical activity among children and adults: A review of qualitative studies. Health Education Research. 2006; 21(6):826-35.

[17]. Jones D, Jones P. Model for success: The impact of a grant-funded program on an inner-city girls' basketball team. The Journal of Physical Education, Recreation, \& Dance. 2002; 73(5):22-6.

[18]. Sport and Recreation Commission, Community Sport Development programme; 2012, (online) retrieved 12 August 2013 from www. Src.org.zw

[19]. Sport and Recreation Commission: Community Sport Development Manual. Belvedere. Harare, 2009.

[20]. Sport and Recreation Commission: Community Sport Development, midterm survey report, Belvedere, Harare, 2010.

[21]. Sport and Recreation Commission: Sport and Recreation Policy of Zimbabwe. SRC: Belvedere. Harare, 1996.

[22]. Ministry of Education, Sports, Arts and Culture National Sports, Arts and Culture Secretary's Circular number 2 of 1994,1994.

[23]. Ministry of Education, Sports, Arts and Culture National Sports, Arts and Culture Secretary's Circular number 5 of 2005,1994.

[24]. Government of Zimbabwe, Sports and Recreation Commission Act, Zimbabwe, 1996.

[25]. Government of Zimbabwe - Department in the Ministry of Youth Development, Gender and employment creation 30 September (2000) The National Youth policy - Zimbabwe (Online) retrieved 26 september 2013 from lanipolis.iiep.unesco.org

[26]. National AIDS Council (Zimbabwe): HIV and AIDs policy, 1999.

[27]. Ogi, A "Sustainable Sport and Development" at the Workshop "Partnership in practice: Assessing our Capacity to Deliver" Garden Court, Cape Town South Africa, 2006.

[28]. The Tripartite Cooperation Agreement, 2007.

[29]. James, J $13^{\text {th }}$ Edition of the annual National sports Awards (ANSA) 2011 Supplement "Heart for success" The Sunday mail Leisure January 22-28, 2012. 